\title{
A contemporary care model for older adults should seek coordinated care, greater quality and the reduction of costs
}

\begin{abstract}
The present text discusses the creation of a health care model for older adults. The population aging arising from Brazil's new demographic and epidemiological reality, a relatively recent phenomenon, requires innovative and efficient responses. This article presents a proposal for care that emphasizes low intensity instances of care, focusing on health promotion, prevention, and the coordination of care. Integrated models aim to solve the problem of fragmented and poorly coordinated care in our current health systems, and the more health professionals know about a patient's history, the better the results. This is how resolutive models of care should function. A low intensity care unit, an epidemiological assessment, a client portfolio, with a doctor and nurse and a few gerontologists on staff, and a social center will make the difference. There will also be a high quality information system, including medical records that cover clinical and social characteristics. Everything is available via cloud computing and the cell phones of the doctors and clients, and high levels of technology and performance based pay for doctors make a further difference. In short, a higher quality, more resolutive and cost-effective care model is our aim.
\end{abstract}

Keywords: epidemiological reality, old age, naturally grow, older adults, higher quality, health standards, chronic and multiple, quality of life, early diagnosis
Volume 3 Issue 5 - 2019

\author{
Renato Veras,' Raquel Cordeiro² \\ 'Medical Doctor, Full Professor of the State University of Rio de \\ Janeiro, Brazil \\ ${ }^{2}$ Executive editor at the University of the Third Age of Rio de \\ Janeiro State University, Rio de Janeiro, Brazil
}

\begin{abstract}
Correspondence: Renato Veras, Medical Doctor, Full Professor of the State University of Rio de Janeiro, State University of Rio de Janeiro, Brazil,Tel 5502I 2334-0|68, Fax 5502I2334-0|68, Email raquelcordeirouerj@gmail.com, unativeras@gmail.com
\end{abstract}

Received: October 06, 2019 | Published: October 15, 2019
Abbreviations: SUS, unified health system; WHO, world health organization; NHS, National Health Service

\section{Introduction}

One of humanity's greatest achievements has been the extension of life span. Reaching old age - once the privilege of the few - has become the norm even in the poorest countries, and has been accompanied by substantial improvements in people's health standards, even though these achievements are far from evenly distributed across countries and socioeconomic contexts. This significant achievement of the twentieth century, however, entails a major challenge - adding quality to those additional years of life. ${ }^{1,2}$ The demographic transition and the improvement in Brazil's social and economic indicators, in comparison with previous decades, have led to a growth in the older adult population and greater fiscal pressure on public and private health systems. If this population group increases, then chronic diseases and spending also naturally grow. One result of this dynamic is the increasing demand for health services, which may, in turn, lead to a scarcity of and/or constraints on resources. Hospital admissions become more frequent and bed occupancy is longer than with other age groups. The diseases that affect older adults are mostly chronic and multiple, requiring constant monitoring and permanent care. ${ }^{3,4}$

In Brazil, we have observed an excess of consultations by specialists, as the current model prioritizes the fragmentation of care and the excessive use of hospitals. Such procedures have a major financial impact at all levels and do not generate significant health or quality of life benefits. ${ }^{5,6}$ The change in the age configuration of the country, with the growth of older adult segment, is a recent phenomenon. But the idea that this is a new concept belongs in the past, along with the well-known, widely-accepted clichés, common even to those who do not work in the area. Talk of theoretical frameworks or policies that aim to enable healthy aging - which means maintaining functional capacity and autonomy, as well as quality of life, in line with the principles and guidelines of the Unified Health System (or SUS) and focusing on the prevention of diseases - is to be commended. Major Brazilian and international health organizations have argued in favor of this concept for many years ${ }^{4}$. Now it is time to act!

\section{Impact and relevance of the work}

Over the past few decades, it has been shown that most of the health problems that affect the population can be prevented - including those related not only to communicable but also to noncommunicable diseases. This statement is evidenced by the significant decrease in mortality from coronary and cerebrovascular diseases, the reduced incidence of and mortality from cervical cancer, as well as a reduction in the prevalence of smoking and the incidence of lung cancer in men. In short: a major disease burden can be avoided in both social and economic terms. ${ }^{7}$ However, quality of care is still undervalued. It is a topic of enormous importance, which demands greater awareness among health professionals and society. It is argued that it is expensive to apply tools that enable the provision of more qualified care and accreditations and certifications, but more qualified services are more cost effective, have less waste and achieve better patient outcomes. In some countries, the accreditation and evaluation of quality indicators are mandatory requirements. In Brazil, however, volume is valued and rewarded because a policy of stimulating quality is lacking. Patients do not always recognize quality as a necessity, while both public and private health care perceive it as an additional cost. 
There is a general understanding that care for older adults goes beyond health. In addition to diagnosis and prescription, social participation and physical and mental activities are extremely important elements for maintaining functional capacity. But there is still, especially in supplementary health, great difficulty in perceiving these actions as an integral part of care. There is a tendency to separate 'social' actions from 'curative' actions. It is also of fundamental importance, especially today, that quality information and medical records are used effectively by doctors and health professionals, allowing constant client monitoring. Many still view the development of preventive action as a burden on procedures that results in additional costs. They should, however, understand this as a reversal of logic, and that in the medium to long term this approach could reduce hospitalizations and other much more costly procedures. All the evidence indicates that biomedicine-based health systems will progressively suffer sustainability issues.

Epidemiological information translates into the ability to predict events, enabling early diagnosis (especially in relation to chronic diseases), delaying the onset of such diseases, improving quality of life and supporting the therapeutic approach. The determination of the health conditions of the older population must take into account overall health status, or in other words, consider a satisfactory level of functional independence and not just the absence of disease. Thus, the concept of functionality should be thought of as a health paradigm of older adults and one of the most important attributes of human aging, as it deals with the interaction between physical and psycho-cognitive abilities to perform activities of daily living. ${ }^{8}$ A contemporary health model for older adults needs to bring together the flux of health education, health promotion, the prevention of preventable diseases, the delayed onset of diseases, early care and disease rehabilitation. A line of care ${ }^{9}$ for older adults which seeks to be effective and efficient should presuppose an articulated, referenced network, with an information system designed in keeping with this logic. We live in the age of technology and information.

Health systems work with few points of care, which then fail to operate in an integrated manner. In general, patients enter this disjointed network at a very advanced stage, with the entry point often being the hospital emergency unit. Such a model, besides being inadequate and anachronistic, has a terrible cost-benefit ratio, since it is hospital-centered, making intensive use of high-cost technologies. Its failure, however, should not be attributed to the clients, but to the care model applied, since there is an overload of users at the most complex levels, due to the lack of care at early stages. The impact and relevance of this study is related to the innovation of a new model of health care for older adults, leaving a fragile and overloaded system behind.

\section{Innovation and the disruptive capacity of the work}

It is easy to talk about the need for a new model of health care for older adults, and the subject is widely discussed. Putting it into practice, however, is a different matter. When a chronic disease is already established the goal should not be a cure, but the pursuit of clinical stabilization and constant monitoring in order to prevent or alleviate functional decline. Programs aimed at this population should be built on the basis of integrative care, with the referring physician and their team occupying a central role, managing not the disease, but the health profile of the client - often the treatment of a particular manifestation can only be conducted with the reduction or suspension of other actions currently being performed. ${ }^{10}$
According to the World Health Organization (WHO), a chronic disease has one or more of the following characteristics: it is permanent; produces disability or disabilities; is caused by irreversible pathological disorders; and needs long periods of supervision, observation or care. Chronic diseases usually start slowly, have a long or uncertain duration, and have several causes rather than a single origin. ${ }^{11}$ Treatment involves lifestyle changes and ongoing care that does not usually lead to a cure, but keeps the disease under control and improves the patient's quality of life. Most chronic diseases are related to age, poor eating habits, physical inactivity and stress, and so most can be prevented. Studies have shown that care must be organized in an integrated manner, and needs to be coordinated along the care pathway, in a logic network that functions from system entry to end-of-life care. ${ }^{12}$ Effective models of health care for older adults, therefore, are those that present a proposal for coordinated care. ${ }^{13}$ Once the risk has been identified, the priority is early rehabilitation to reduce the impact of chronic conditions on functionality - intervention is sought before the injury occurs. The idea is to monitor health, not disease; the intention is to postpone the disease, so that older adults can enjoy their longer life with quality. Thus, the best strategy for the proper care of such adults is to use a logic of permanent health monitoring, always keeping the patient under observation, varying only the levels, intensity and setting of the intervention. ${ }^{14}$

In international structures, the generalist or family doctor fully treats $85 \%$ to $90 \%$ of their patients, without the need for the action of a specialist. In addition, health professionals with specific training (in Nutrition, Physiotherapy, Psychology or Speech Therapy) can be called upon. Thus, the older patient will have a much wider range of professionals at their disposal, but it is their doctor who makes recommendations and referrals. ${ }^{15}$ In Brazil, there is an excess of consultations by specialists, as the current model of care prioritizes the fragmentation of care. ${ }^{16}$ This is evidenced, for example, in comparisons with the English model, the National Health Service (NHS), which has as its central organizational figure so-called general practitioners (GPs), physicians with a high-resolutive capacity who establish a strong bond with the patient. England's public health care system is offered to all citizens regardless of income or social status, similar to the SUS.${ }^{17}$ To be entitled to free public medical care, people must register with a general practitioner. Care units are local health clinics composed of general practitioners and nurses. Any necessary medical care, provided it is not extremely urgent or due to an accident, will be performed by the doctor of this health center. The American model, in turn, opts for referral to numerous medical specialists, contrary to the English approach. These are two rich countries with a long tradition in medicine that use different models and provide very different result. ${ }^{18}$

One of the subjects of great interest to the health sector and to geriatrics and gerontology is the health care of older adults. The discussion about population aging brought about by the new epidemiological and demographic reality leads (or should lead) to the development of a resolute and effective model of health care for older adults. ${ }^{19}$ Another innovative issue relates to the model of remuneration for health professionals. As it is accepted that they are underpaid, why not adopt performance based pay? Associating the discussion of results with the form of compensation is a powerful incentivizing tool in the search for an efficient solution. Thus, "performance-based-pay" and "results-based-pay" are synonymous in the struggle for alignment between access and quality of care. Changing the compensation model based on this new framework of care, focused on results rather than volume, must necessarily be a win-win model, in which 
everyone involved benefits, especially the patients themselves. It is not enough to change the remuneration model without changing the care model and vice versa, as the two are interdependent. The important thing when choosing a differentiated remuneration model is that it is appropriate to the type of care performed and the objective to be achieved. Over the years of applying a particular care model associated with a model of compensation, an entire health system is shaped and programmed towards a particular end. This is the main discussion to be had.

Some of the problems of the Brazilian health system, especially the supplementary system, which primarily affect older adults, are a consequence of the model adopted decades ago. To cope with this new and urgent societal need, alternative remuneration models must be implemented to break the vicious circle of a succession of fragmented consultations, decontextualized from the social and health reality of older adults, as well as the implementation of procedures that are disconnected from the expected outcome. If everyone is debating this issue and solutions are already on the table, why does the situation remain unchanged? Why does theory not translate into everyday life? Why do leaders and managers not promote change?

\section{Scope, applicability and reproducibility}

In the field of Collective Health, epidemiological information translates into the ability to predict events, enabling early diagnosis (especially in relation to chronic diseases), delaying the onset of these diseases, improving quality of life and supporting the therapeutic approach. ${ }^{20}$ The role of the health professional, in these cases, is not to prevent the disease (as it is already installed) or to seek a cure, but to seek stabilization and the reduction of harm, aimed at maintaining quality of life. ${ }^{10}$ It is agreed that greater knowledge of patient history among health professionals leads to more positive results. This statement is endorsed by the WHO and all the managers and professionals of the area. As reasonable as it is old, it is a concept that continues to represent what is most modern in terms of health care models. What is surprising is that, although accepted by all, it is not put into practice in everyday life.

The main risk factor of most chronic diseases that affect older adults is old age itself. Growing old without any type of chronic disease is the exception rather than the rule. Thus, the focus of any contemporary policy should be on promoting healthy aging, maintaining and improving - where possible - the functional capacity of older adults, preventing disease, restoring the health of the sick (or stabilizing illnesses) and rehabilitating those who have their functional capacity restricted. Actions like these, however, are still somewhat limited. The largest investment remains in traditional care practice, with emphasis on the hospital structure. ${ }^{14}$

A health unit with broader characteristics allows some problems to be anticipated, from the early identification of symptoms, mood swings or possible functional losses. Thus, the older adult can be immediately referred to the doctor responsible for their care. ${ }^{1,2}$ Ideally, health care services should be geared towards providing qualified care and well-being for older adults, with clients having a referring physician and all doctors having a client portfolio for which they are responsible. This loyalty brings excellent results, both clinical and financial. The location of this care unit can be a space with the characteristics of a social center where there are various activities: medical consultations and actions of integration and participation, facilitating trust and customer loyalty to the model. This "innovation" has existed in England since 1948.
As detailed in the actions, the differentiation between high and low intensity instances of care is clear. The model proposes to work only with low intensity instances, or in other words, it does not include high intensity care, and will not be responsible for the hospital, emergency unit, medical specialists, or complementary examinations. Thus, the model will act in the care and follow-up of clients, via the doctor and nurse, the gerontology team and the social center. When a specialist doctor is required, the client's doctor will refer them to the specialist and in return receive all the information about the procedures performed, as this client doctor is the centralizer of care, similar to the English GP. It is important to note that there is no limitation of care. The success of this model is based on good general practitioners, and for more complex cases which only a specialist can resolve, this client is referred to such a doctor. There are therefore no restrictions, and the concern is to provide adequate and necessary care in order to reduce waste. A specialist should only be used for something special! In the case of hospitalization, the general practitioner will contact the hospital doctor and the nurse will remain in contact with the hospital and family members, providing all necessary assistance to the patient's relatives, obtaining all the required information and facilitating communication with the family. This simple care procedure adds value by providing and facilitating effective support for the client and their family, as they feel protected and informed about everything that is going on. ${ }^{20}$

Although several healthcare actions are not considered part of this model, it is expected that more than $85 \%$ of clients in this portfolio will be low-intensity users. Therefore we intend to change the logic through which health plans operate, as with this intensity of care we hope to diminish the use of hospitals and/or reduce the length of hospital stays, the excessive use of specialist doctors, and unnecessary examinations requested by numerous medical specialists. By caring for and accompanying our clients with trained and qualified professionals we are able to keep the vast majority of patients in "low-intensity" services with only a few, for the shortest possible time, moving to high-intensity instances. In this configuration, the model shares the care of its affiliates with a healthcare operator, and in low-intensity instances it offers higher quality care, more frequent monitoring, client and family loyalty, at a lower cost and with better care results. It is important to stress that while the healthcare provider's clients will not lack anything, the results of this structure are much better, both for the client and their family, as well as for the healthcare provider itself.

The program is structured through a care model that emphasizes comprehensive care and prevention through the continuous monitoring of health conditions and the coordination of care at all care settings. The focus is on health promotion and prevention in order to stabilize chronic diseases to avoid system overload. ${ }^{21-24}$ It is based on a pairing formed of a generalist doctor (qualified geriatrician) and a gerontology nurse, who together are responsible for monitoring the health of a client portfolio. In health units, an important space is the social center, which plays a fundamental role as a place for the integration of various educational, promotion and prevention actions. There are meetings and interactions mediated by pedagogical intentions aimed at older adults, with health workshops, therapeutic groups, yoga, ballroom dancing, cognitive stimulation, psychology groups, nutrition, singing, postural orientation, pelvic and muscular strengthening, all conducted by professionals from a multidisciplinary team who contribute specific tools from their area of knowledge and performance. The purpose of setting up a social center within a health center is to reduce the problems of loneliness in older adults, 
improving their social contact and allowing them to develop new skills at an older age, as it is a stimulating space for the exchange of experiences, mediated through a pedagogical context. ${ }^{21}$

\section{Use of lightweight technology and technology as a differential}

There needs to be a high quality information system and lightweight technology to help build customer loyalty. Without the use of technology, the project is not viable, so the skills to make the most of its potential must be available. ${ }^{22}$ One example: the client, when entering through the front door of the health center, has their face identified, which instantly opens their medical record on the receptionist's desk. Upon receiving this, the receptionist greets the patient by name, asks about their family, and checks the list of medicines they are taking. These are extremely simple actions, but they add tremendous confidence to the relationship, making the client feel protected and welcomed from the first moment. Recording the care pathway of the patient is another strong differentiating factor. A comprehensive and quality information system is able to document not only the clinical evolution of older adults, but also their participation in individual or collective prevention actions, as well as the support of the nurse and phone calls, which should be resolutive, performed by trained and qualified personnel. Telephone contact between patients and professionals should be carried out with the full sharing of information with the team, for the benefit of a complete individual assessment.

The information system, which begins with the registration of the beneficiary, is one of the pillars of the program. Through it, the entire care pathway is monitored at each level, ensuring the effectiveness of actions and contributing to decision making and follow-up care. It is a single, longitudinal and multi-professional electronic record, which accompanies the client from the outset. This record differs from existing medical records in that there is a registry of the patient's life history and health events.

Another important differential is the availability of a mobile app with individualized information bulletins and reminders of appointments and prescribed actions. The app may, among other actions, ask the customer to take a picture of their breakfast and send it to a nutritionist, who will check if the food is balanced, or if there is adequate fiber, and so forth. Every effort will be made to maintain users within the units of the program, without the use of specialists.

\section{Conclusion}

In summary, an efficient health care model for older adults should involve all levels of care, that is, incorporate a well-designed flow of education, health promotion, the prevention of preventable disease, the delayed onset of illnesses, the provision of care as early as possible and the rehabilitation of injuries. This line of care begins in the catchment process, in reception, and only ends in the final moments of life, in the palliative care unit. The socioeconomic transformations of recent decades and the consequent alterations in the lifestyles of individuals in contemporary societies - with changes in eating habits, a more sedentary lifestyle and increased stress, as well as the growing life expectancy of the population - contribute to a higher incidence of chronic diseases, which today constitute a serious public health problem. The current provision of health services, as set out at the beginning of this article, fragments the care of older adults, overloads the system, has a serious financial impact at all levels and does not generate significant benefits for quality of life. The population is older, diseases are chronic and multiple, care costs are increasing, care models date from the era of acute illness, and knowledge of epidemiology informs us about risk factors. So why do we continue to offer an outdated and ineffective product if there is sufficient information to implement a care model in which everyone wins? All that is required to redirect the health care of older adults and build an organization within the sector that provides better care and economic-financial results is for all involved to feel themselves responsible for making the necessary changes and to allow themselves to innovate - which, in many situations, means salvaging simple care and values that have been lost within our healthcare system. Finally, it is imperative that the healing and caring debate is included in discussions about vocational training and service organization. The structure for caring for people needs to be organized in a health system that has so far focused on healing patients. This will make a major difference in this era of population aging. It is possible to grow old with good health and quality of life!

\section{Acknowledgments}

None.

\section{Funding details}

None.

\section{Conflicts of interest}

The author declares there is no conflict of interest.

\section{References}

1. Veras RP, Oliveira M. Aging in Brazil: the building of a healthcare model. Cien Saude Colet. 2018;23(6):1929-1936.

2. Veras RP, Estevam AA. Modelo de atenção à saúde do idoso: a ênfase sobre o primeiro nível de atenção. In: Lozer AC et al. editors. Conhecimento técnico-científico para qualificação da saúde suplementar. Brasília, DF: OPAS; 2015. p. 73-84.

3. Szwarcwald CL, Damacena GN, De Souza Júnior PRB, et al. Percepção da população brasileira sobre a assistência prestada pelo médico. Ciênc Saúde Colet. 2016;21(2):339-350.

4. Veras RP. International experiences and trends in health care models for the elderly. Cien Saude Colet. 2012;17(1):231-238.

5. Veras RP, Oliveira MR. Linha de cuidado para o idoso: detalhando o modelo. Rev Bras Geriatr Gerontol. 2016;19(6):887-905.

6. Arai H, Ouchi Y, Yokode M, et al. Toward the realization of a better aged society: messages from gerontology and geriatrics. Geriatr Gerontol Int. 2012;12(1):16-22.

7. Veras RP. Caring Senior: um modelo brasileiro de saúde com ênfase nas instâncias leves de cuidado. Rev Bras Geriatr Gerontol. 2018;21(3):1-7.

8. Béland F, Hollander MJ. Integrated models of care delivery for the frail elderly: international perspectives. Gac Sanit. 2011;25 (Suppl 2):138-146.

9. Carvalho VKS, Marques CP, Silva EN. A contribuição do Programa Mais Médicos: análise a partir das recomendações da OMS para provimento de médicos. Ciênc Saúde Colet. 2016;21(9):2773-2784.

10. Moraes EN. Atenção à saúde do idoso: aspectos conceituais. Brasília, DF: OPAS; 2012. p. 1-102.

11. Box G. Understanding and responding to demand in English general practice. Br J Gen Pract. 2016;66(650):456-457. 
12. Veras RP, Oliveira M. Envelhecer no Brasil: a construção de um modelo de cuidado. Ciênc Saúde Colet. 2018;23(6):1929-1936.

13. Veras RP, Oliveira MR. Linha de cuidado para o idoso: detalhando o modelo. Rev Bras Geriatr Gerontol. 2016;19(6):887-905.

14. Mendes EV. As redes de atenção à saúde. Brasília, DF: OPAS; 2011. p. $1-554$.

15. Oliveira MR, Da Silveira PD, Neves R, et al. Idoso na saúde suplementar: uma urgência para a saúde da sociedade e para a sustentabilidade do setor. Rio de Janeiro: ANS; 2016. p. 1-12.

16. Veras RP, Caldas CP, Da Motta LB, et al. Integração e continuidade do cuidado em modelos de rede de atenção à saúde para idosos frágeis. Rev Saúde Pública. 2014;48(2):357-365.

17. Veras RP. Experiências e tendências internacionais de modelos de cuidado para com o idoso. Ciênc Saúde Colet. 2012;17(1):231-238.

18. Silva AMM, Mambrini JVM, Peixoto SV, et al. Uso de serviços de saúde por idosos brasileiros com e sem limitação funcional. Rev Saúde Pública. 2017;51(Suppl 1):1-10.
19. 19 Box G. Understanding and responding to demand in English general practice. Br J Gen Pract. 2016;66(650):456-457.

20. Oliveira MR, Veras RP, Cordeiro HA. Supplementary Health and aging after 19 years of regulation: where are we now? Rev Bras Geriatr Gerontol. 2017;20(5):624-633.

21. Oliveira MR, Mambrini JVM, Peixoto SV, et al. A mudança de modelo assistencial de cuidado ao idoso na Saúde Suplementar: identificação de seus postos-chave e obstáculos para implementação. Physis. 2016;26(4):1383-1394.

22. Veras PR, Gomes JAC, Macedo ST. A coordenação de cuidados amplia a qualidade assistencial e reduz custos. Rev Bras Geriatr Gerontol. 2019;22(2):e1900073.

23. Oliveira M, Veras RP. Um modelo eficiente no cuidado à pessoa idosa. Correio Brasiliense. Brasília, 27 ago. 2015: Seção Opinião. 2015. p. 13.

24. Abicalaffe CL. Pagamento por performance: o desafio de avaliar o desempenho na área da saúde. J Bras Econ Saúde. 2011;3(1):179-185. 